\title{
Kinematic analysis of Felix Baumgartner's Stratospheric Jump in 2012
}

\author{
Josemaria Zavala ${ }^{1}$ and Jimmy Menendez ${ }^{1 \#}$ \\ ${ }^{1}$ Los Alamos High School, Jesus Maria, Lima, Peru \\ \#Advisor
}

\section{$\underline{\text { ABSTRACT }}$}

The present investigation shows a kinematic analysis of Baumgartner's stratospheric jump, based on a scientific report by Red Bull. The modeling was carried out using the different forces that intervened in the event (velocity, acceleration, etc.), making it possible to generate a mathematical model capable of extrapolating data and allowing us a better appreciation of such scientific achievement. All the mathematical exploration has been carried out with ten decimal places; however, they will be rounded to four in writing. The action plan was based on obtaining the velocities by placing points on a velocity model belonging to an approximate graph of a Red Bull scientific report, which was put into the GeoGebra Classic 5 program to find the velocities. After this, we proceeded to find the accelerations and the formula of the function that models them. Finally, this formula was integrated to acquire the mathematical model of the velocities.

\section{Introduction}

On October 14, 2012, the Austrian Felix Baumgartner became the first man to break the sound barrier, having jumped into the void from a height of more than 39,000 meters without the support of any vehicle or type of propellant. An achievement that years before we might have considered impossible. In a Red Bull scientific report on Felix Baumgartner's stratospheric jump, they mentioned that the maximum vertical velocity occurs in 50 seconds of free fall, reaching a velocity of $377.1 \mathrm{~m} / \mathrm{s}$. However, according to what has been studied, the velocity is found by multiplying the time by the intensity of the earth's gravitational field $\left(9.81 \mathrm{~m} / \mathrm{s}^{2}\right)$, obtaining a value in the second 50 of $490.5 \mathrm{~m} / \mathrm{s}$, a value unequal to the one mentioned previously. Consequently, this would not be a uniformly accelerated rectilinear motion.

These events are the ones that give rise to questions such as: How could the velocities and accelerations experienced by Felix be modeled? Would a function that models the accelerations and velocities experienced by Baumgartner be fluid or disjointed? Interrogations like these lead us to obtain the functions that model all the velocities $^{1}$ and accelerations ${ }^{2}$ acting on the Austrian paratrooper throughout the movement. It should be noted that different mathematical elements will intervene, such as functions by parts, derivatives, integrals, and analysis of functions; therefore, I relied on the Red Bull scientific report ${ }^{3}$ to carry out the study, giving me the velocities experienced throughout the fall. In addition, using the support of GeoGebra, I was able to place the figure on the scale as proposed in the image.

\footnotetext{
${ }^{1}$ It is a physical magnitude that relates the position of an object or living being with time

${ }^{2}$ It is a vector derived quantity that relates the variation of velocity with time

3 "Red Bull Stratos Summary Report", Red Bull (February 4, 2020) Accessed on August 24, 2020.Available at: https://issuu.com/redbullstratos/docs/red_bull_stratos_summit_report_final_050213
} 


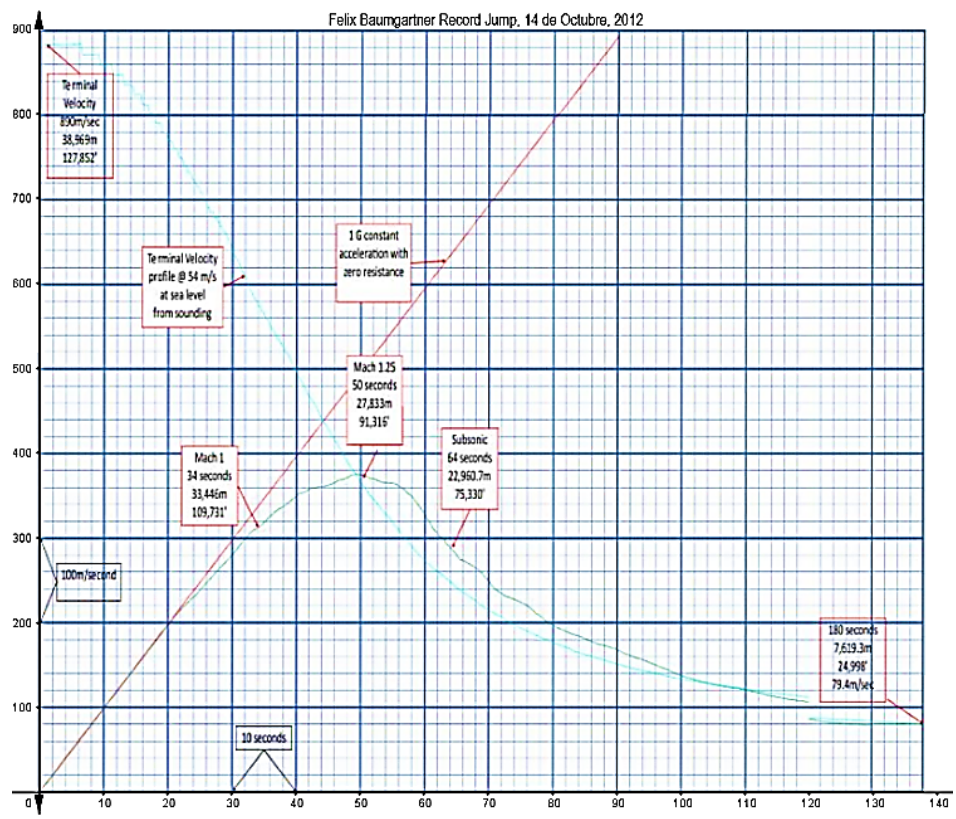

Figure 1. Official Red Bull image adjusted on a GeoGebra Cartesian plane showing some forces that intervened in Felix Baumgartner's stratospheric jump

\section{Methodology}

As a first step, I obtained data from Figure 1 by placing a series of points in order (see Figure 2). In this way, we can bring the velocities experienced by Baumgartner over time.

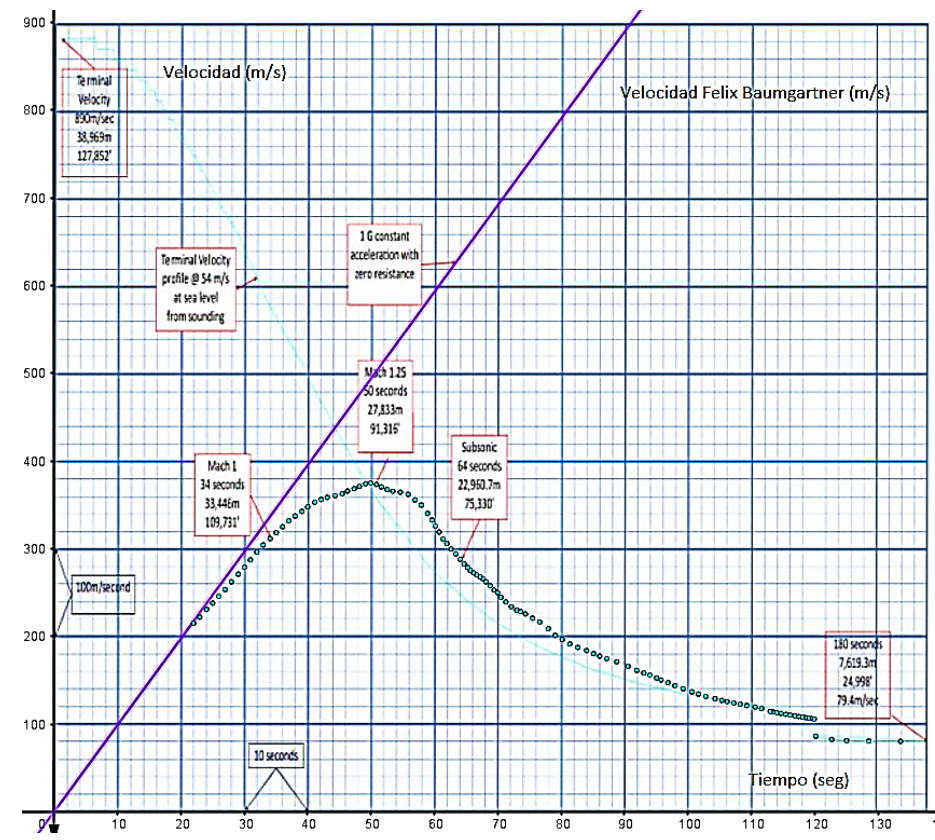

Figure 2. Graph taken from Red Bull and adjusted on a GeoGebra Cartesian plane that models the velocities experienced by Felix Baumgartner in the stratospheric jump. 
Using these data, we can obtain a model through regression with all velocities. However, by proceeding in this way, the formula for the velocity function is achieved but disjointed. Therefore, when deriving the velocity, the acceleration came out the same way. When this problem arose, I decided to find a mathematical model for the accelerations as the first specific objective.

This model will be approximate, since I will obtain it through the average rate of change ${ }^{4}$, which I will discover using the following formula:

$\frac{d_{V}}{d_{t}} \approx \frac{\Delta_{V}}{\Delta_{t}}=\frac{V_{2}-V_{1}}{t_{2}-t_{1}} ;$ : velocity $\mid t:$ time

The data I obtained using this technique gives me average change ratios that are approximately equivalent to the derivative existing at the midpoint of that time interval. Added to this, the average rate of change of a function gives us an idea of how much it decreases or increases in a given interval. The average variation rate would be the acceleration as a velocity function since it tells us if the velocity increases or decreases depending on the time. However, to generate a scatter plot, we need the independent variable. This time, it will be the classmark, the midpoint of an interval representing all the values. The use of the classmark is given for the calculation of some parameters. Therefore, this would come representing the $\mathrm{X}$-axis.

To determine the class marks, I used the following formula:

$M_{c}=\frac{t_{1}+t_{2}}{2} ; M_{c}:$ Class Mark $\mid t:$ time

After having the values of the accelerations and the class marks, I made a scatter diagram in GeoGebra.

\begin{tabular}{|c|c|c|c|}
\hline \multicolumn{2}{|c|}{ Estadisticas $\vee$} & \multirow{2}{*}{\multicolumn{2}{|c|}{ Diagrama de dispersión $\vee$}} \\
\hline MediaX & 757016 & & \\
\hline MediaY & -1.4678 & \multirow{8}{*}{\multicolumn{2}{|c|}{ Y: L214:L326 }} \\
\hline Sx & 35.0373 & & \\
\hline Sy & 5.1768 & & \\
\hline$r$ & -0.3329 & & \\
\hline$\rho$ & -0.2656 & & \\
\hline nVarX & 137492.2678 & & \\
\hline nVarY & 3001.4985 & & \\
\hline \multirow[t]{2}{*}{$\mathrm{nCov}$} & -6763.1088 & & \\
\hline & & $\mathrm{X}: \mathrm{K} 214: \mathrm{K} 326$ & \\
\hline
\end{tabular}

Figure 3. Scatter diagram made in GeoGebra that shows the accelerations experienced by Felix Baumgartner in the stratospheric jump

As we can see in figure 3, the acceleration has a defined form; however, it is difficult to adapt to a single function. Consequently, it would be helpful to model it in parts, dividing the acceleration into three mathematical models. We can observe three abrupt changes, one between 17 and 21 seconds and the other around 60 seconds. In addition, they will be chosen from the best correlation coefficient that presents the best fit. It is worth mentioning that the first model was not counted in the previous figure because, at first glance, its integral (velocity) is observed that it is linear, with a slope of 9.875, as can be corroborated in Figure 2. Therefore, when it is derived, I will also get a linear function with a slope of 0 . Thus, the first mathematical model of acceleration has the following formula:

$$
A_{1}(t)=9.875
$$

For the second mathematical model, I made a two-variable regression from $t=0.05$ to $t=60.4866$, since as previously mentioned, around second 60 , there is a noticeable change in acceleration; the accelerations start to

${ }^{4}$ It is the slope of a line that crosses the coordinates of an interval 
decrease and then begin to increase sharply. It should be noted that I incorporated the points of the first mathematical model in such a way it would fit better.

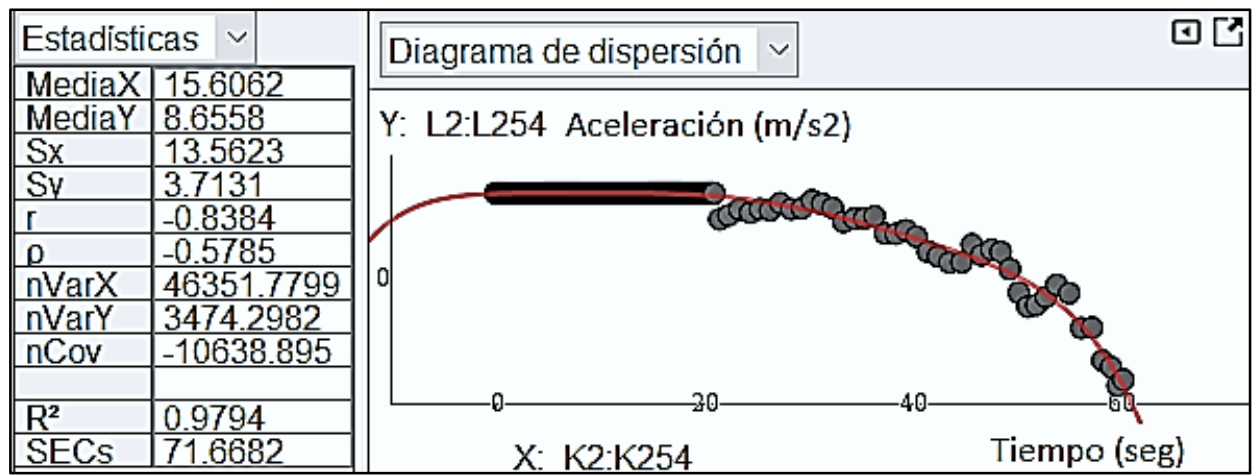

Figure 4. Scatter diagram made in GeoGebra showing the Felix Baumgartner accelerations in the stratospheric jump from second 0.05 to second 60.4866

Figure 4 is being modeled by a function of degree 6 , chosen due to the value of its coefficient of determination $\left(R^{2}=0.9794\right)$ since it is the one that best suits the situation and covers the most significant number of values. This is defined with the following formula:

$$
A_{3}(t)=-83 \times 10^{-10} t^{6}+1179 \times 10^{-9} t^{5}-0.0001 t^{4}+0.0012 t^{3}-0.0098 t^{2}+0.0353 t+9.839
$$

In the case of the third mathematical model, we have to consider the notion of terminal velocity ${ }^{5}$, which takes place when the force of gravity ${ }^{6}$ equates to the force of air resistance ${ }^{7}$, that is, the velocity becomes constant, being represented by a horizontal asymptote. After searching, I found data that the terminal velocity, in the Felix Baumgartner stratospheric jump was $175 / 3\left(\mathrm{~m} / \mathrm{s}^{2}\right)^{8}$.

However, we are not working with velocity in this part but with acceleration. However, this data helps us to establish the mathematical model to use, in this case, a potential function, which given the circumstances, should tend to 0 , but why not a rational or exponential function? A rational function could not be since it contains a vertical and horizontal asymptote. On this occasion, the vertical asymptote would get in my way and make me too complicated. On the other hand, exponential could be. However, for the technique I wanted to use, it was better to use a potential, which was also ideally suited to the given circumstances.

If the velocity graph is represented by a horizontal asymptote of $175 / 3$, the acceleration graph will have to be represented by a horizontal asymptote of 0 so that the velocity tends to be constant. This third mathematical model would start from $\mathrm{A}_{3}$ ended and finish at 180 seconds (Red Bull graph limit). To find the function's formula, a natural logarithm was applied to the class mark and the accelerations, which acquired a linear function format when one superimposes a natural logarithm to a potential function, with which it is easier to work. However, in second 60.4866

\footnotetext{
${ }^{5}$ It is the constant velocity achieved by an object or living being that falls through a resistant medium and in which a constant force act.

${ }^{6}$ It is a force generated by objects with mass to attract each other.

${ }^{7}$ It is the force that opposes the force of gravity when the body moves through the air.

${ }^{8}$ Naukas, "Baumgartner's jump, step by step” by Arturo Quirantes. Accessed August 4, 2020. Available at: https://naukas.com/2012/10/21/el-salto-baumgartner-paso-apaso/\#: :text=Seg\%C3\%BAn\%20esta\%20gr\%C3\%A1fica\%2C\%20Baumgartner\% 20recorri\% C3\% B3, from\% 20 about $\% 20210 \% 20 \mathrm{~km} \% 2 \mathrm{Fh}$.
} 
and onwards, the acceleration was negative, so the negative natural logarithm was applied to the acceleration $(\ln [-$ aceleración $])$.With these new values, we plotted a scatter plot.

\begin{tabular}{|c|c|c|c|}
\hline Estadistic & icas $\vee$ & Diagrama de dispersión $\vee$ & 묻 \\
\hline \begin{tabular}{|l} 
MediaX \\
MediaY \\
\end{tabular} & \begin{tabular}{|l}
4.5111 \\
0.9738
\end{tabular} & Y: $02: 074$ & \\
\hline & 0.2777 & +0.014 & \\
\hline \begin{tabular}{|l}
$\mathrm{p}$ \\
$\mathrm{p}$ \\
\end{tabular} & \begin{tabular}{|l|l|}
-0.9268 \\
\end{tabular} & & \\
\hline \begin{tabular}{|l}
$\rho$ \\
nVarX $X$ \\
nVarY
\end{tabular} & $\frac{-0.9549}{5.5532}$ & 0 & \\
\hline $\begin{array}{l}\text { nVary } \\
\text { nCov } \\
\end{array}$ & 67.9974 & & \\
\hline nCov & -18.0114 & & \\
\hline $\begin{array}{l}\mathrm{R}^{2} \\
\mathrm{SECS}\end{array}$ & 0.859 & & \\
\hline SECs & 9.5849 & $X:$ N2:N74 & \\
\hline Modelo d & de regresió & & \\
\hline Lineal & $\checkmark$ & $y=-3.2431 x+15.6038$ & \\
\hline
\end{tabular}

Figure 5. Scatter diagram made in GeoGebra showing the Felix Baumgartner accelerations in the stratospheric jump influenced by a $\ln (-x)$ from second 60.4866 to second 180 .

Using the linear function, we can reverse the process because, in reality, the discovered formula would be:

$$
\begin{gathered}
\ln \left(A_{5}(t)\right)=-3.2431 \ln (t)+15.6038 \\
A_{5}(t)=e^{-3.2431 \ln (t)}+e^{15.6038} \\
A_{5}(t)=e^{-3.2431 \ln (t)+15.6038}
\end{gathered}
$$

Then, it would have to be reflected with the $\mathrm{x}$-axis so that it fits with the function A3, obtaining the following:

$$
\begin{gathered}
A_{5}(t)=-e^{-3.2431 \ln (t)+15.6038} \\
A_{5}(t)=-e^{15.6038} t^{-3.2431} \\
A_{5}(t)=-5979215.9184 t^{-3.2431}
\end{gathered}
$$

After having the three mathematical models, I continued with their union:

$$
\begin{aligned}
& A(t) \\
& =\left\{\begin{array}{c}
A_{1}(t)=9.875: 0 \leq t<21.15 \\
A_{3}(t)=-83 \times 10^{-10} t^{6}+1179 \times 10^{-9} t^{5}-0.0001 t^{4}+0.0012 t^{3}-0.0098 t^{2}+0.0353 t+9.839: 21.15 \leq t<60.4866 \\
A_{5}(t)=-5979215.9184 t^{-3.2431}: 60.4866 \leq t \leq 180
\end{array}\right.
\end{aligned}
$$

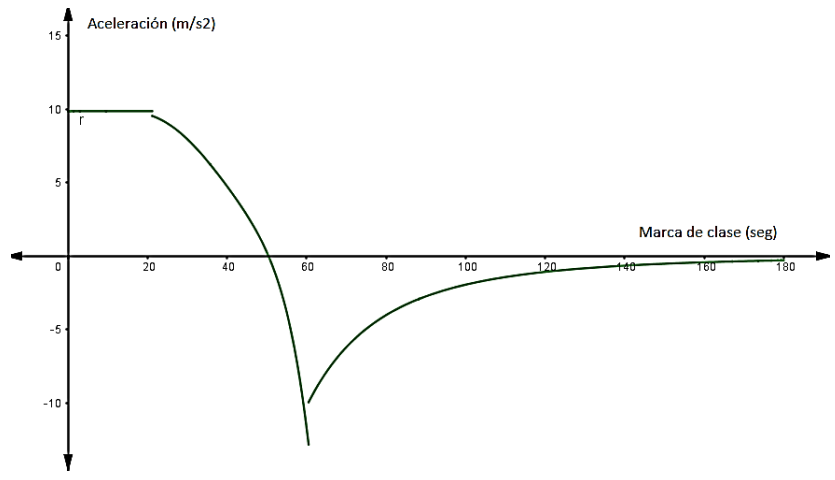

Figure 6. Modeling of the acceleration, carried out in GeoGebra, experienced by Felix Baumgartner in the stratospheric jump up to 180 seconds. 
As can be seen in figure 6, the acceleration model is disconnected. After presenting this problem, I decided to unite the parts that are not connected through functions that are appropriate to the situation, and the use of these makes sense. Therefore, to join the function $\mathrm{A}_{1}$ with $\mathrm{A}_{3}$, I used the polynomial interpolation technique using a cubic function, and for the coupling of the function $\mathrm{A}_{3}$ with $\mathrm{A}_{5}$, the same, but instead, I used a fourth-degree function. I determined that the cubic function would start from the second 17.3 to 18.3, since being disjointed in the same second, I will use from half a second before and half a second after. Therefore, to find the formula of the function, I made a system of equations, considering the structure of a cubic function:

$$
f(t)=g t^{3}+h t^{2}+i t+j
$$

The coordinate $(17.3,9.875)$ belonged to the function $A_{1}$, which means that if we wanted to join $A_{1}$ with $A_{3}$ through a cubic function, by replacing $t$ by 17.3 , we should obtain 9.875 , obtaining the following as the first equation:

$$
9.875=g(17.3)^{3}+h(17.3)^{2}+i(17.3)+j
$$

Then, by replacing $t$ by 18.3 in the cubic function, we should obtain A3 (18.3), acquiring the following formula as the second:

$$
9.7653=g(18.3)^{3}+h(18.3)^{2}+i(18.3)+j
$$

As I needed two more equations, I decided to derive the functions $A_{1}$ and $A_{3}$, thus arriving at the force of Jolt ${ }^{9}$, better known as jerk. Consequently, when deriving the functions $\mathrm{A}_{1}$ and $\mathrm{A}_{3}$, I obtained the following:

$$
\begin{gathered}
J_{1}(t)=0 \\
J_{3}(t)=-498 \times 10^{-10} t^{5}+58949 \times 10^{-10} t^{4}-0.0002 t^{3}+0.0035 t^{2}-0.0196 t+0.0353
\end{gathered}
$$

In addition, I took into account the structure of the derivative of a cubic function.

$$
\mathrm{f}^{\prime}(\mathrm{t})=3 g \mathrm{t}^{2}+2 \mathrm{ht}+\mathrm{i}
$$

Finding the third equation by replacing $\mathrm{t}$ with 17.3 , it should come out 0 since 17.3 belongs to the function $\mathrm{A}_{1}$, the integral of $\mathbf{J}_{1}$.

Obtaining the following as the third equation:

$$
0=3 g(17.3)^{2}+2 h(17.3)+i
$$

Finally, to find the fourth equation, by replacing t with 18.3, J3 (18.3) would have to come out. Obtaining as the fourth equation the following:

$$
-0.0531=3 g(18.3)^{2}+2 h(18.3)+i
$$

After this, I obtained the following system of equations:

$$
\left\{\begin{array}{c}
9.875=\mathrm{g}(17.3)^{3}+\mathrm{h}(17.3)^{2}+\mathrm{i}(17.3)+\mathrm{j} \\
9.7653=\mathrm{g}(18.3)^{3}+\mathrm{h}(18.3)^{2}+\mathrm{i}(18.3)+\mathrm{j} \\
0=3 \mathrm{~g}(17.3)^{2}+2 \mathrm{~h}(17.3)+\mathrm{i} \\
-0.0531=3 \mathrm{~g}(18.3)^{2}+2 \mathrm{~h}(18.3)++\mathrm{i}
\end{array}\right.
$$

This was solved using the GeoGebra program, finding the values of the variables:

$$
g=0.1663 ; h=-8.9042 ; i=158.8162 ; j=-933.4923
$$

Having the values, they were replaced, obtaining the cubic function that joins $A_{1}$ with $A_{3}$, denoting it with the name of $\mathrm{A}_{2}$.

$$
A_{2}(t)=0.1663 t^{3}-8.9042 t^{2}+158.8162 t-933.4923 ; 17.3 \leq t<18.3
$$

As a next step, I needed to find the fourth-degree function that connects $\mathrm{A}_{3}$ with $\mathrm{A}_{5}$. A quartic function was chosen because, unlike $\mathrm{A}_{2}$, there are three points of interest, the two points at the end of the connection and a minimum point experienced approximately in the second 60.5, as shown in figure 3. Being a fourth-degree function, five equations will be needed to obtain the values of all the variables.

\footnotetext{
${ }^{9}$ It is the variation of the acceleration with respect to time; the derivative of the acceleration.
} 
I determined that the function is from $t=60$ to $t=61$ since the function $\mathrm{A}_{3}$ and $\mathrm{A}_{5}$ were unconnected in the second 60.4866 , approximately 60.5 , so I also used a transition second between one and the other function, half a second before and a half a second later. Also, remember the structure of a fourth-degree function:

$$
f(t)=b t^{4}+c t^{3}+d t^{2}+e t+f
$$

The point with $t=60$ belonged to the function $\mathrm{A}_{3}$; this point would also form part of the fourth-degree function, which means that if we replaced $t$ by 60 , we had to obtain $\mathrm{A}_{3}(60)$. Getting the following equation:

$$
-11.7461=b(60)^{4}+c(60)^{3}+d(60)^{2}+e(60)+f
$$

The point with $t=61$ belonged to the function $\mathrm{A}_{5}$, so if we replaced $\mathrm{t}$ by 61 , we had to obtain $\mathrm{A}_{5}(61)$. Bringing the following equation:

$$
-9.6980=b(61)^{4}+c(61)^{3}+d(61)^{2}+e(61)+f
$$

The point $t=60.5$ also belonged to the function $\mathrm{A}_{5}$, so if we replaced t by 60.5 , we had to obtain $\mathrm{A}_{5}(60.5)$. Receiving the following equation:

$$
-12.8742=b(60.5)^{4}+c(60.5)^{3}+d(60.5)^{2}+e(60.5)+f
$$

Having three equations and missing two, I decided to go back to the topic of Jolts. However, in this case, I only needed to bypass $A_{3}$ and $A_{5}$. We must take into account the structure of a fourth-degree function that has been derived:

$$
f^{\prime}(t)=4 b t^{3}+3 c t^{2}+2 d t+e
$$

By deriving $\mathrm{A}_{3}$ and $\mathrm{A}_{5}$, I got the following:

$$
\begin{gathered}
J_{3}(t)=-498 \times 10^{-10} t^{5}+58949 \times 10^{-10} t^{4}-0.0002 t^{3}+0.0035 t^{2}-0.0196 t+0.0353 \\
J_{5}(t)=\frac{121194969656019}{6250000} \times \frac{t}{t^{4}\left(t^{\frac{1}{10000}}\right)^{9999}\left(t^{\frac{1}{625}}\right)^{152}} ; 60 \leq t<61
\end{gathered}
$$

To get the fourth equation by replacing $t$ with 60 in function $\mathrm{J}_{3}$, I get $\mathrm{J}_{3}(60)$. Getting as the fourth equation:

$$
-2.1797=4 b(60)^{3}+3 c(60)^{2}+2 d(60)+e
$$

To obtain the fifth equation, we replace $t$ by 61 in function $\mathrm{J}_{5}$, so I get $\mathrm{J}_{5}(61)$. Getting as the fifth equation:

$$
0.5156=4 b(61)^{3}+3 c(61)^{1}+2 d(61)+e
$$

After this, the following system of equations was obtained:

$$
\left\{\begin{aligned}
-11.7461 & =b(60)^{4}+c(60)^{3}+d(60)^{2}+e(60)+f \\
-9.6980 & =b(61)^{4}+c(61)^{3}+d(61)^{2}+e(61)+f \\
-12.8742 & =b(60.5)^{4}+c(60.5)^{3}+d(60.5)^{2}+e(60.5)+f \\
-2.1797 & =4 b(60)^{3}+3 c(60)^{2}+2 d(60)+e \\
0.5156 & =4 b(61)^{3}+3 c(61)^{1}+2 d(61)+e
\end{aligned}\right.
$$

Which was solved with the GeoGebra program, obtaining the values of the variables:

$$
b=-29.0429 ; c=7022.6211 ; d=-636764.2426 ; e=25660463.46 ; f=-387766737.4
$$

By having the values of the variables, they were replaced in the structure of a fourth-degree function that joins $\mathrm{A}_{3}$ with $\mathrm{A}_{5}$, denoting it with the name of $\mathrm{A}_{4}$.

$$
A_{4}(t)=-29.0429 t^{4}+7022.6211 t^{3}-636764.2426 t^{2}+25660463.46 t-387766737.4
$$

Once all the mathematical models of the accelerations experienced by Felix Baumgartner in the stratospheric jump had been obtained, we proceeded to join them. In this way, a "general" acceleration function would be received:

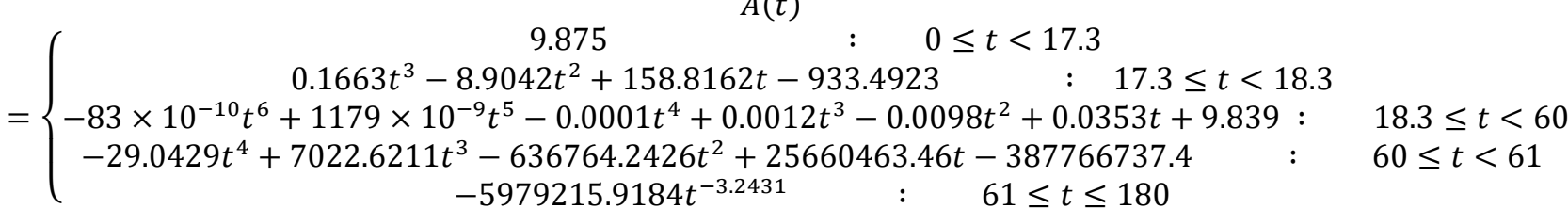

After getting it, we moved to graph it. 


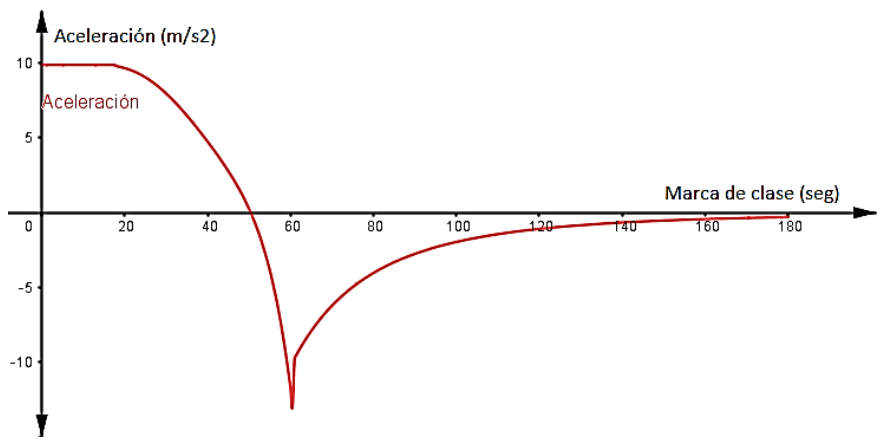

Figure 7. Modeling of the accelerations, carried out in GeoGebra, experienced by Felix Baumgartner in the stratospheric jump up to 180 seconds.

In figure 7, it can be observed all the accelerations throughout the movement. On the other hand, the abrupt change in the second 60.5 is highlighted. Likewise, we can notice the horizontal asymptote of the function $\mathrm{A}_{5}(y=$ $0)$, since as time passes, Baumgartner gets closer to reaching its terminal velocity $(175 / 3 \mathrm{~m} / \mathrm{s})$. It is worth mentioning that linear acceleration is observed at the beginning of the jump until 17.3 seconds; in that period, it is highlighted that the acceleration would be the intensity of the earth's gravitational field $(9.875 \mathrm{~m} / \mathrm{s})$, that is, free fall.

As a second step, we will integrate $\mathrm{A}(\mathrm{t})$ to find the function that models the velocities. However, it has to be integrated into parts. In addition, it must be taken into account that when integrating a function, its independent variable will become 0 , so it will be necessary to move the functions so that they fit correctly.

The first step would be to integrate $A_{1}$. When intersecting the coordinate $(0,0)$, it is not necessary for us to manipulate it, so the integral of this would be the first velocity model:

$$
\begin{aligned}
A_{1}(t) & =9.875 \\
\int 9.875 d t & =9.875 t+c
\end{aligned}
$$

Given that $V_{1}(0)=0, \quad V_{1}(t)=9.875 t ; 0 \leq t<17.3$

The second step would be to integrate $\mathrm{A}_{2}(\mathrm{t})$. In this way, we will find the indefinite integral. Likewise, we also have the data that $V_{1}(17.3)=V_{2}(17.3)$; therefore, the independent value (c) of the integrated function can be found, thus fulfilling the equality as mentioned above.

$$
\begin{gathered}
A_{2}(t)=0.1663 t^{3}-8.9042 t^{2}+158.8162 t-933.4923 \\
V_{2}(t)=\int 0.1663 t^{3}-8.9042 t^{2}+158.8162 t-933.4923 d t \\
V_{2}(t)=0.0416 t^{4}-2.9681 t^{3}+79.4081 t^{2}-933.4923 t+c
\end{gathered}
$$

Since $V_{1}(17.3)=V_{2}(17.3)$, then we have:

$$
9.875(17.3)=0.0416(17.3)^{4}-2.9681(17.3)^{3}+79.4081(17.3)^{2}-933.4923(17.3)+c
$$

Therefore:

$$
V_{2}(t)=0.0416 t^{4}-2.9681 t^{3}+79.4081 t^{2}-933.4923 t+4195.8864 ; 17.3 \leq t<18.3
$$

The third step would be to integrate $\mathrm{A}_{3}(\mathrm{t})$, just like $\mathrm{A}_{2}(\mathrm{t})$. On this occasion, we have the data that $V_{2}(18.3)=V_{3}(18.3)$. Therefore, we can obtain the value of $\mathrm{c}$.

$$
A_{3}(x)=-83 \times 10^{-10} t^{6}+1179 \times 10^{-9} t^{5}-0.0001 t^{4}+0.0012 t^{3}-0.0098 t^{2}+0.0353 t+9.839
$$

$\int-83 \times 10^{-10} t^{6}+1179 \times 10^{-9} t^{5}-0.0001 t^{4}+0.0012 t^{3}-0.0098 t^{2}+0.0353 t+9.839 d t$ elue Vetenemos quealdad mencionadapendiente de la funcir acio largo del movimiento. 8888888888888888888888888888888888888888

$V_{3}=-12 \times 10^{-10} t^{7}+1965 \times 10^{-10} t^{6}-118483 \times 10^{-10} t^{5}+0.0003 t^{4}-0.0033 t^{3}+0.0177 t^{2}+9.839 t+c$ Given that $V_{2}(18.3)=V_{3}(18.3)$ 


$$
\begin{gathered}
181.48824=-12 \times 10^{-10} t^{7}+1965 \times 10^{-10} t^{6}-118483 \times 10^{-10} t^{5}+0.0003 t^{4}-0.0033 t^{3}+0.0177 t^{2} \\
+9.839 t+c \quad c=0.0059
\end{gathered}
$$

Therefore:

$$
\begin{gathered}
V_{3}(t)=-12 \times 10^{-10} t^{7}+1965 \times 10^{-10} t^{6}-118483 \times 10^{-10} t^{5}+0.0003 t^{4}-0.0033 t^{3}+0.0177 t^{2}+9.839 t \\
+0.0059 ; 18.3 \leq t<60
\end{gathered}
$$

The fourth step would be to integrate $\mathrm{A}_{4}(\mathrm{t})$. In this case, we have the data that $V_{4}(60)=V_{3}(60)$ so, we can find the value of $\mathrm{c}$

$$
\begin{gathered}
A_{4}(t)=-29.0429 t^{4}+7022.6211 t^{3}-636764.2426 t^{2}+25660463.46 t-387766737.4 \\
\int-29.0429 t^{4}+7022.6211 t^{3}-636764.2426 t^{2}+25660463.46 t-387766737.4 d t \\
V_{4}(t)=-5.8086 t^{5}+1755.6553 t^{4}-212254.7475 t^{3}+12830231.7299 t^{2}-387766737.3738 t+c
\end{gathered}
$$

Given that $V_{3}(60)=V_{4}(60)$ :

$$
\begin{gathered}
-5990.5002=-5.8086(60)^{5}+1755.6553(60)^{4}-212254.7475(60)^{3}+12830231.7299(60)^{2} \\
-387766737.3738(60)+c \\
c=4687655010.2998
\end{gathered}
$$

Therefore:

$$
\begin{gathered}
\mathrm{Vel}_{4}(t)=-5.8086 t^{5}+1755.6553 t^{4}-212254.7475 t^{3}+12830231.7299 t^{2}-387766737.3738 t \\
+4687655010.2998 ; 60 \leq t<61
\end{gathered}
$$

The fifth step would be to integrate $\mathrm{A}_{5}$. For this function, we have as data that $V_{4}(61)=V_{5}(61)$ with the use of this data, we can obtain the value of $\mathrm{c}$.

Given that $V_{4}(61)=V_{5}(61)$ :

$$
\begin{gathered}
A_{5}(\mathrm{t})=-5979215.9184 t^{-3.2431} \\
\int_{V_{5}(t)}-5979215.9184 t^{-3.2431} d t \\
=2665603.8154 t^{-2.2431}+c
\end{gathered}
$$

Therefore:

$$
\begin{aligned}
-16484.2229 & =2665603.8154(61)^{-2.2431}+c \\
c & =-16748.9303
\end{aligned}
$$

$$
V_{5}(t)=2665603.815 t^{-2.2431}-16748.9303 ; 61 \leq t \leq 180
$$

Once we had the five functions that model the velocities experienced by Felix Baumgartner, we proceeded to join them, converting them into a mathematical model of general velocity:

$$
V(t)\left\{\begin{array}{c}
9.875 t ; 0 \leq t<17.3 \\
0.0416 t^{4}-2.9681 t^{3}+79.4081 t^{2}-933.4923 t+4195.8864 ; 17.3 \leq t<18.3 \\
-12 \times 10^{-10} t^{7}+1965 \times 10^{-10} t^{6}-118483 \times 10^{-10} t^{5}+0.0003 t^{4}-0.0033 t^{3}+0.0177 t^{2}+9.839 t+0.0059 ; 18.3 \leq t \\
-5.8086 t^{5}+1755.6553 t^{4}-212254.7475 t^{3}+12830231.7299 t^{2}-387766737.3738 t+4687655010.2998 ; 60 \leq t< \\
2665603.815 t^{-2.2431}-16748.9303 ; 61 \leq t \leq 180
\end{array}\right.
$$

The function V (t) was graphed. Obtaining the following:

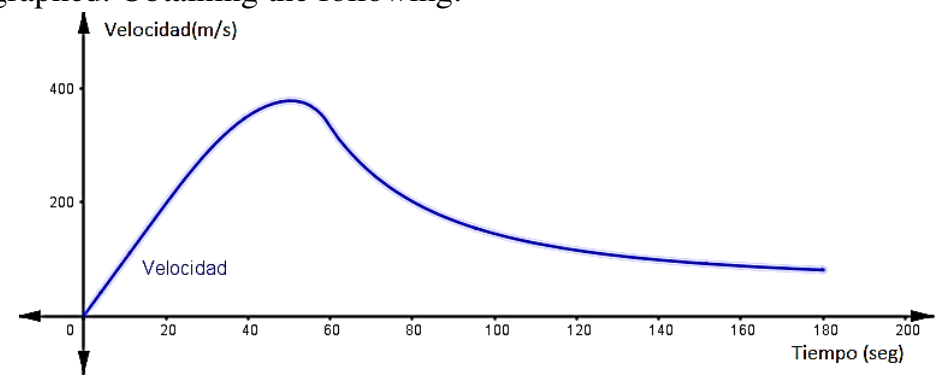

Figure 8. Modeling of velocities, carried out in GeoGebra, experienced by Felix Baumgartner in the stratospheric jump up to 180 seconds

Employing the present mathematical model of velocity (Figure 8), we can obtain all the velocities throughout the movement that Felix Baumgartner experiences. In addition, a linear increase is observed since it is only affected by the intensity of the earth's gravitational field $(9.875 \mathrm{~m} / \mathrm{s})$. Furthermore, no air resistance is present from second 0 
to second 17.3. On the other hand, as time passes, a horizontal asymptote belonging to the $\mathrm{V}_{5}$ function is observed; the velocity each time approaches the value of the terminal velocity $175 / 3 \mathrm{~m} / \mathrm{s}$.

\section{Conclusion}

In the present work, I managed to fulfill the research objective, which is to find mathematical models for the accelerations and velocities experienced by Felix Baumgartner in the stratospheric jump.

Throughout the work, I faced various difficulties, such as the acceleration being obtained in a disjointed way and, therefore, the velocity, justified by the fact that it is a leap out of the ordinary, as Felix Baumgartner ends up breaking what would become the sound barrier. In addition, various variables such as density, air resistance, paratrooper posture, turbulence, etc., come into play in the movement. Likewise, this work is unique and complete since it allows us to put together different mathematical topics, linking them to possible solutions to the problems that arise. This exploration is of great importance in the current historical and global context, as it is a cinematic study of one of the most recognized skydiving jumps in the world. Studying velocities and accelerations is very common in the scientific community, as these data initiate improvements and new projects.

The mathematical fields present were: algebra and calculus, which were of utmost importance to achieve the objective of the work. It should be noted that this research also has a weakness, and that is that the Red Bull graph, as I mentioned at the beginning of the work, is approximate and not entirely accurate. However, the work also has strengths, as is an analysis of various sources that served to contrast data. In the case of limitations, one of these was the period; my work was based from the second 0 to the second 180. However, the stratospheric jump in total lasted "4 minutes and 36 seconds" Another limitation is the terminal velocity, which starts a debate, as the Red Bull page never mentions anything about it. Also, some sources even say that there was never a terminal velocity present. These limitations, in turn, give rise to extensions (improvements); one of these can be to carry out a kinematic study of the complete Felix Baumgartner jump ( 4 minutes and 36 seconds) ${ }^{10}$. Likewise, another extension could be to study the force of Jolt. On the other hand, it would also be interesting to do a similar job with the jump of Alan Eustace ${ }^{11}$. He beats Baumgartner's record jumping from the stratosphere with a height of 41,150 meters, although he does not exceed sound velocity

\section{Acknowledgments}

The author thanks Magister Jimmy Menéndez for guiding him to carry out this research and develop skills that will serve him for future works.

\section{References}

[1] "Red Bull Stratos Summary Report", Red Bull (February 4, 2020) Accessed August 24, 2020. Available at: $\underline{\text { https://is- }}$ suu.com/redbullstratos/docs/red bull stratos summit report final 050213

${ }^{10}$ RTVE, "Jump from the stratosphere Felix Baumgartner manages to break the sound barrier in his stratospheric jump" by Ramón Pizarro. Accessed August 4, 2020.Available at: https://www.rtve.es/deportes/20121014/felix-baumgartnerlograromperbarreradelsonidosusaltoestratosferico/570070.shtml\#: :text=Felix\%20Baumgartner\%20super $\%$ C3\%B3\%20el\%20anterior,cuatro $\% 20$ minutos $\% 20 \mathrm{y} \% 2036 \% 20$ segundos.

${ }^{11}$ BBC, "Google executive Alan Eustace breaks Felix Baumgartner's jumping record" written by BBC world. Accessed August 4, 2020.Available at:

https:/www.bbc.com/mundo/noticias/2014/10/141025_google_alan_eustace_record_altura_men 
[2] Naukas, "Baumgartner's jump, step by step" by Arturo Quirantes. Accessed August 4, 2020.Available at:https://naukas.com/2012/10/21/el-salto-baumgartner-paso-a-paso/\#: :text=Seg\%C3\%BAn\%20esta\%20gr\%C3\%A1fica\%2C \%20Baumgartner\%20recorri\%C3\%B3,de\%20unos $\% 20210 \% 20 \mathrm{~km} \% 2 \mathrm{Fh}$.

[3] RTVE, "Jump from the stratosphere Felix Baumgartner manages to break the sound barrier in his stratospheric jump" by Ramón Pizarro. Accessed August 4, 2020.Available at:https://www.rtve.es/deportes/20121014/felix-baumgartnerlograromperbarreradelsonidosusaltoestratosferico/570070.shtm|\#: : :text=Felix\%20Baumgartner\%20super\%C3\%B3\%20el\%20anterior,cuatro\% 20 minutos $\% 20 \mathrm{y} \% 2036 \% 20$ segundos.

[4] BBC, "Google executive Alan Eustace breaks Felix Baumgartner's jumping record" written by BBC world. Accessed August 4, 2020.Available at: https://www.bbc.com/mundo/noticias/2014/10/141025 google alan eustace record altura men 